\title{
Efeitos de dominância linguística e de tempo de exposição formal à língua na produção de pronomes clíticos por crianças bilingues português/francês ${ }^{1}$
}

\author{
Margarida Tomaz ${ }^{*}$ Maria Lobo ${ }^{*}$, Ana Madeira*, Carla Soares-Jesel ${ }^{* *}$ \& Stéphanie Vaz ${ }^{*}$ \\ "NOVA FCSH/CLUNL, ${ }^{* *}$ Université Paris Diderot/LLF
}

\begin{abstract}
:
This study investigates the effects of two external linguistic variables - language dominance and time of formal exposure - on the production and placement of clitic pronouns of Portuguese-French bilingual children. Using two elicited production tasks and a parental sociolinguistic questionnaire, we show that language dominance plays a role in rates of omission and rates of clitic production. On the other hand, a higher time of formal exposure to Portuguese does not determine better performance neither in what concerns clitic omission nor clitic placement in Portuguese-French bilingual children.
\end{abstract}

Keywords: Language dominance, formal exposure, bilingual children, clitics, Portuguese, French

Palavras-chave: Dominância linguística, exposição formal, crianças bilingues, português, francês

\section{Introdução}

Em estudo anterior (Tomaz et al., 2019), centrado na aquisição de pronomes clíticos por crianças bilingues português/francês, concluímos que, globalmente, o desenvolvimento bilingue não difere substancialmente do desenvolvimento monolingue, corroborando o que demonstraram estudos realizados nas décadas de 80 e 90 (Meisel, 1989; Genesee, 1989; e.o.). No entanto, existe um desenvolvimento mais lento na produção de clíticos, que se traduz em taxas de omissão superiores no grupo de bilingues, confirmando o que foi encontrado em outros estudos sobre outros pares de línguas (Costa, Lobo \& Pratas, 2016; Nardelli \& Lobo, 2017, 2018; PérezLeroux, Pirvulescu \& Roberge, 2018; e.o.). Na análise dos resultados de grupo da tarefa de colocação de clíticos, verificámos ainda que o grupo de bilingues produziu taxas significativamente mais altas de próclise em contexto de ênclise. Contudo, uma análise individual dos resultados permitiu-nos perceber que o grupo de bilingues apresenta resultados heterogéneos, o que nos levou a explorar agora o efeito de outras variáveis extralinguísticas no desempenho dos participantes. Para este estudo, escolhemos analisar dois fatores extralinguísticos: a dominância linguística (DL) e o tempo de exposição formal à língua (TEF). A importância destas variáveis no desenvolvimento de diferentes aspetos gramaticais continua a ser discutida na literatura (Unsworth 2014; Thordardottir, 2014; Thomas et al., 2014; Flores \& Correia 2016; Rodina et al., 2020; e.o.).

O artigo está organizado da seguinte forma: na secção 2 , fazemos uma breve revisão da aquisição, por crianças bilingues, das duas propriedades que consideramos no estudo; na secção 3 , descrevemos os fundamentos teóricos das duas variáveis extralinguísticas aqui em análise; na secção 4, apresentamos as questões e hipóteses de investigação que sustentam o nosso estudo; a secção 5 é dedicada à descrição da

\footnotetext{
${ }^{1}$ Trabalho realizado no âmbito do projeto PESSOA 2017/19, 38033ZL (FCT, Ministério francês da Europa e dos Negócios Estrangeiros, Ministério francês da Educação Nacional, Ensino Superior e Investigação) da Bolsa de Doutoramento KRUse atribuída a Margarida Tomaz (PD/BD/113973/2015), e do Projeto Estratégico do CLUNL (UID/LIN/03213/2013) e parte do programa "Investissements d'Avenir", supervisionado pela Agência Nacional Francesa de Investigação, ANR-10-LABX-0083 (Labex EFL).

Agradecemos aos participantes no XXXV Encontro Nacional da APL as observações feitas e aos revisores anónimos os comentários à primeira versão do artigo, que nos permitiram melhorar a versão final.
} 
metodologia do estudo; na secção 6, são apresentados os resultados obtidos; e, finalmente, na secção 7, fazemos uma discussão dos resultados e apresentamos as conclusões.

\section{Aquisição de clíticos por crianças bilingues português-francês}

Embora o português europeu (PE) e o francês partilhem algumas características sintáticas, também diferem noutras tantas. No caso específico do nosso objeto de estudo, a aquisição de clíticos, estas duas línguas diferem, pelo menos, no que diz respeito aos contextos em que a omissão do clítico é permitida e nos padrões de colocação de clíticos. Relativamente à omissão, a principal diferença é o facto de o PE permitir objetos nulos (de terceira pessoa) desde que estes dois pressupostos ocorram: os objetos nulos possam ser recuperados discursivamente e não ocorram em ilhas sintáticas (Raposo, 1986). No francês, por sua vez, o objeto nulo é lexicalmente condicionado, uma vez que só pode ocorrer com alguns verbos (Tuller, 2000).

Relativamente à colocação de clíticos, no PE a colocação é regida por restrições sintáticas, oscilando entre a ênclise e a próclise. A ênclise é o padrão básico, enquanto a próclise ocorre na presença de elementos, como a negação, orações completivas, advérbio já, entre outros (Martins, 2013; e.o.). No francês, o padrão de colocação é a próclise, ocorrendo a ênclise apenas em contextos de uso da forma imperativa negativa.

O fenómeno do bilinguismo tem sido amplamente discutido na literatura com principal foco na questão de saber como se processa o desenvolvimento bilingue e se a aquisição bilingue é semelhante à aquisição monolingue. Ainda que desde há muito se defenda que o desenvolvimento bilingue não difere substancialmente do desenvolvimento monolingue (Meisel, 1989; Genesee, 1989; e.o.), ainda se discute a importância de fatores linguísticos e extralinguísticos nesse desenvolvimento, e em particular as possíveis influências de uma língua sobre a outra.

Os vários estudos que envolvem a aquisição de clíticos apontam para que todas as crianças passam por um estádio em que a omissão de objeto ocorre e que é transversal a todas as línguas. No entanto, existem línguas em que este estádio cessa cedo, outras, como o caso do francês, em que a omissão diminui por volta dos $4 / 5$ anos (Pérez-Leroux et al., 2008). No caso do PE, este estádio prolonga-se até muito mais tarde quando comparado com as restantes línguas (Costa \& Lobo, 2006; Costa, Lobo \& Silva, 2009; Silva, 2008; Varlokosta et. al., 2015). As crianças bilingues, tal como as monolingues, também passam pelos mesmos estádios de aquisição e desenvolvimento que os monolingues. No entanto, monolingues e bilingues distinguem-se essencialmente porque os últimos, regra geral, apresentam taxas de omissão mais elevadas. Taxas superiores de omissão de clíticos ou de pronomes objeto em bilingues foram observadas quer em estudos com dados de produção espontânea (Müller \& Hulk, 2001; e.o.), quer em estudos de produção induzida (Costa, Lobo \& Pratas, 2016; Nardelli, 2015; Nardelli \& Lobo, 2017, 2018; Pérez-Lerouz et al., 2018; Rinke, Flores \& Sopata, 2019; Tomaz et al., 2019 e.o.). Todos estes trabalhos mostram, para diferentes pares de línguas, que as crianças bilingues omitem mais o objeto do que as crianças monolingues em tarefas de produção induzida, havendo, contudo, uma sensibilidade a contextos sintáticos semelhante à dos monolingues.

$\mathrm{Na}$ colocação de clíticos, na maioria das línguas, encontram-se geralmente produções-alvo desde cedo. Em línguas em que o padrão de colocação é a próclise, como o francês, ou em línguas em que a colocação do clítico depende da finitude das orações, como o espanhol, o italiano ou o grego padrão, as crianças não apresentam erros de colocação (Guasti, 1993/1994; Hamann et al., 1996; Marinis, 2000; Wexler, Gavarró \& Torrens, 2004). No entanto, em PE as crianças em idade de aquisição mostram alguns erros de colocação que se traduzem na generalização da ênclise em contextos de próclise (Costa, Fiéis \& Lobo, 2015). Este desenvolvimento mais tardio da colocação de clíticos no PE justifica-se pelo facto de, nesta língua, a colocação estar diretamente dependente de propriedades lexicais e sintáticas especificas e não da finitude das orações como acontece em outras línguas. No caso do desenvolvimento bilingue, estes falantes seguem um padrão de desenvolvimento de colocação de clíticos semelhante ao dos monolingues. No entanto, o processo de aquisição 
tem tendência para ser mais lento e tardio, uma vez que estes falantes estão expostos a um input mais reduzido e mais ambíguo, por haver não só variação dentro da língua, mas também sobreposição parcial entre sistemas linguísticos. Tal como os monolingues, os bilingues passam por um estádio de generalização da ênclise e também adquirem os contextos de próclise de forma progressiva, mas a estabilização dos padrões de colocação de clíticos é mais tardia (Barbosa \& Flores, 2011; Flores \& Barbosa, 2014; Casa Nova, 2015; Flores, Barbosa \& Casa Nova, 2016).

\section{Dominância linguística e tempo de exposição formal à língua}

Apesar de se defender desde há muito que o desenvolvimento bilingue não difere substancialmente do desenvolvimento monolingue e que os processos são semelhantes (Meisel, 19089; Genesee, 1989; e.o.), não é ainda totalmente claro qual o papel que desempenham fatores extralinguísticos nesse desenvolvimento. $\mathrm{Na}$ verdade, os efeitos de input no desenvolvimento bilingue têm sido amplamente discutidos na literatura. Diversos estudos têm investigado a importância do input, quer em termos quantitativos, quer qualitativos, no desenvolvimento de aspetos de diferentes componentes linguísticas - fonologia, léxico, morfossintaxe, sintaxe e semântica. Se é inegável que a quantidade e qualidade do input (incluindo diversidade de contextos e de registos em que a língua é usada e a que a criança está exposta) tem influência no desenvolvimento lexical (Thordardottir, 2011; De Houwer et al. 2014; Flores \& Correia, 2016), já não é tão claro o papel que pode ter no desenvolvimento morfossintático. Unsworth et al. (2014) mostram que há propriedades gramaticais mais vulneráveis do que outras a efeitos de exposição ao input. Propriedades gramaticais de aquisição tardia parecem ser mais vulneráveis do que propriedades de aquisição precoce. Sendo a produção e colocação de clíticos um aspeto de desenvolvimento tardio no português, dependente não só de conhecimento sintático, mas também discursivo e lexical, é esperável que esta seja uma área vulnerável a efeitos de input.

Não é simples determinar a quantidade e qualidade do input que uma criança recebe em cada língua. Têm surgido várias propostas para calcular esse perfil, havendo vários autores que procuram calcular o peso relativo de cada uma das línguas a que a criança está exposta, com base na quantidade e diversidade de contextos de uso de cada língua, determinando assim um índice de DL.

A DL é geralmente definida na literatura tendo como base dois fatores. Um dos fatores tem que ver com a proficiência, ou seja, com o nível de conhecimento que o falante tem de cada uma das línguas por ele faladas. O outro fator está relacionado com o uso da língua, que se traduz na frequência de uso de cada uma das línguas em conjugação com os contextos em que cada uma das línguas é usada no seu dia-a-dia (Wang, 2013; TreffersDaller, 2019). No entanto, há quem defenda que a definição de DL se baseia num único fator como a quantidade de input recebido em cada língua (Argyri \& Sorace, 2007), na experiência pessoal em cada uma das línguas (Kootsra \& Doedns, 2016), ou ainda na língua a que o falante recorre com mais frequência (Silva-Corvalán \& Treffers-Daller, 2016). No entanto, podemos verificar que entre todas estas possibilidades de definições do termo DL há um denominador comum: o uso, ou a frequência de uso de cada uma das línguas. Na verdade, este cálculo é mais complexo do que parece, uma vez que o falante pode preferir usar a língua A num contexto e a língua B noutro contexto. Segundo o Princípio da Complementaridade (Grosjean, 1997), a DL de cada bilingue é determinada em função de cada um dos domínios específicos do uso das suas línguas, ou seja, os falantes bilingues adquirem e usam as suas línguas com diferentes propósitos e em diferentes domínios da sua vida. Assim, um falante bilingue usará no contexto $\mathrm{X}$ a língua $\mathrm{A}$, no contexto $\mathrm{Y}$ a língua $\mathrm{B}$ e no contexto $\mathrm{Z}$ poderá usar a língua A e a língua B. Apesar disso, várias propostas têm procurado determinar um índice global de DL, tendo em conta informação sobre os diferentes contextos de uso da língua pelo falante.

Tal como referido acima, discute-se a importância do input e da variável DL em particular no desenvolvimento morfossintático. Kupisch (2008), num estudo com duas crianças bilingues alemão-francês que permitiu estudar, entre outros aspetos, a DL, conclui que a influência entre línguas existe independentemente 
da DL. No caso concreto de um dos informantes, que tinha como língua dominante o francês, verificou-se que a DL influenciou de forma positiva a aquisição dos determinantes em alemão. Por sua vez, no caso da outra informante que tinha como língua dominante o alemão, esta não só não influencia de forma negativa a aquisição de determinantes em francês como a sua exposição ao francês parece ter um efeito positivo no desenvolvimento dos determinantes em alemão, embora o francês seja a sua língua mais fraca.

Noutro estudo, Puig-Mayenco et al. (2018) examinaram o papel da DL na competência linguística de bilingues em idade adulta. Os autores mostraram que a DL tem mais influência em certos domínios gramaticais do que em outros, independentemente do grau de DL. Os dados do referido estudo seguem a linha da hipótese de Polinsky $(2016,2018)$, que aponta para que certos domínios gramaticais não sejam vulneráveis a efeitos bilingues mesmo quando considerada a língua minoritária do falante bilingue, ao passo que outros domínios gramaticais são altamente sensíveis a efeitos bilingues.

É, assim, discutida a relevância da variável DL para o desenvolvimento de diferentes propriedades gramaticais, em particular no domínio da morfossintaxe.

De acordo com a literatura, a DL pode ser medida através de variáveis morfossintáticas, lexicais, fonéticas e fonológicas, podendo ser avaliada com recurso a tarefas como: nomeação (Picture Naming Task); extensão média de enunciado (Mean length of utterance - MLU); diversidade/riqueza lexical (Lexical diversity/richness); fluência, velocidade e automaticidade de fala (Fluency, speed, automacity); questionários sociolinguísticos que permitem aceder a informações relativas ao uso e exposição à língua. No presente estudo, recorremos a um questionário sociolinguístico para determinar a DL dos participantes, como descreveremos na secção 5.

Uma outra variável que tem sido considerada no desenvolvimento bilingue, em particular em contextos em que uma das línguas é minoritária, como é o caso dos falantes de herança, é o efeito que tem o ensino formal.

Entre outros aspetos, os falantes bilingues em contextos de língua de herança distinguem-se dos falantes monolingues por não receberem input da L1 como língua societal maioritária e, consequentemente, pela ausência de exposição ou menor exposição à variedade padrão em contexto de ensino formal. Muitos destes falantes não têm a oportunidade de frequentar escolas em que haja ensino formal em ambas as línguas e, portanto, estão limitados ao input fornecido pelo contacto com a variedade coloquial numa das suas línguas. Sabendo que o registo formal difere do coloquial, existem determinados aspetos gramaticais que só estão presentes na norma standard e, consequentemente, só estão acessíveis através do ensino formal. Por esse mesmo motivo, a ausência de determinadas estruturas no input destes falantes é determinante para o desenvolvimento da língua que não é língua oficial do país. Relativamente à importância da exposição formal à língua, Haman et. al (2017) mostraram, num estudo que investigou o desempenho de falantes bilingues polaco-inglês em domínios como a gramática, a fonologia, o processamento e o discurso, que esta variável extralinguística tem mais impacto no desempenho dos falantes bilingues em tarefas de produção e menos impacto em tarefas de compreensão.

O estudo de Pires \& Rothman (2009), que testou o conhecimento de infinitivos flexionados com emigrantes brasileiros de segunda geração que não estiveram expostos ao ensino formal, residentes nos EUA, revela que os participantes têm um défice no conhecimento da estrutura em questão. Os autores defendem que a ausência de determinadas estruturas no input a que o falante está exposto, em conjugação com o facto de não estarem expostos ao ensino formal da língua, tem impacto no desenvolvimento da língua de herança destes falantes.

No caso específico da aquisição de clíticos, Barbosa \& Flores (2011), que testaram a colocação de clíticos por falantes de herança alemão-português, concluíram que a exposição formal à língua não condiciona $o$ desempenho dos falantes nesta tarefa. Grohmann et al. (2017), que também testaram a colocação de clíticos por crianças bilingues (ou bidialectais) grego standard-grego cipriota, colocam a hipótese de que a escolarização influencia a colocação de clíticos. Ambas as variedades diferem quanto ao padrão de colocação básico: o grego standard tem como padrão básico a próclise enquanto na variedade cipriota o padrão de colocação não marcado 
é a ênclise. Sendo a variedade standard do grego a variedade ensinada na escola, os autores preveem que o ensino sistemático desta variedade faça aumentar o uso da próclise no grego cipriota. Os autores concluem que as crianças mais novas fazem uso da ênclise em grego cipriota e, à medida que a escolarização aumenta, a ênclise diminui e a próclise aumenta. No entanto, as diferenças encontradas entre os dois estudos referidos podem dever-se ao facto de em Barbosa \& Flores (2011) se ter analisado o efeito do TEF ao português, que não é a língua de escolarização principal e à qual as crianças estão expostas, de modo formal, apenas durante um número muito reduzido de horas por semana, ao passo que em Grohmann et al. (2017) se considerou como fator de análise o efeito da língua de escolarização, o grego standard, ou seja, a única língua a que as crianças têm exposição formal.

É possível que a exposição ao ensino formal tenha mais efeito quando os participantes são avaliados em idade adulta do que quando testados em crianças, uma vez que, nestas idades, o processo de aquisição ainda está em curso. Para além disso, é esperado que o TEF seja relevante sobretudo em estruturas que necessitam de exposição a registos mais formais para se desenvolverem ou que beneficiem de ensino explícito da língua. Não é claro que o desenvolvimento da produção e colocação de clíticos na variedade europeia do português precise de ensino formal, mas há certamente efeitos de ensino formal em padrões de colocação como a mesóclise, determinados contextos de próclise, e possivelmente também na produção de clíticos. Na variedade brasileira do português, são muito claros os efeitos do ensino formal no desenvolvimento de clíticos acusativos.

O TEF é, por norma, calculado com recurso ao número de horas totais de aulas da língua ou número de anos de exposição formal até ao momento em que o falante é testado.

\section{Questões e hipóteses de investigação}

Tendo em conta a investigação anterior sobre efeitos de input no desenvolvimento bilingue e sobre as variáveis DL e TEF, em particular, e considerando que os pronomes clíticos são um fenómeno de desenvolvimento tardio no português, e, por conseguinte, mais vulnerável a efeitos de input, neste estudo colocamos as seguintes questões:

i) a dominância linguística influencia o desempenho das crianças bilingues português-francês na produção e colocação de clíticos?

ii) o tempo de ensino formal em português influencia o desempenho das crianças bilingues portuguêsfrancês na produção e colocação de clíticos quando as crianças são testadas em português?

Relativamente às hipóteses de investigação e tendo em conta que estamos a testar dois tipos de fenómenos - produção e colocação de clíticos - colocamos as seguintes hipóteses:

a) Dominância linguística

Tendo em conta que a maioria dos estudos sobre bilingues falantes de herança mostra que apenas as crianças que usam a língua minoritária em casa com ambos os pais, e que têm, portanto, maior exposição à língua minoritária, têm resultados próximos dos monolingues (Meisel, 2007; Gathercole \& Thomas, 2009; Paradis, Tremblay \& Crago, 2014; Gathercole et al., 2013; Thomas et al., 2014; Flores, Santos, Jesus \& Marques, 2017), espera-se que as crianças do subgrupo PE dominante tenham taxas de omissão inferiores às dos restantes grupos. No que concerne à colocação de clíticos, espera-se que o subgrupo PE dominante tenha padrões mais próximos dos monolingues, com generalização da ênclise a contextos de próclise, e que o subgrupo FR dominante tenha um padrão de colocação mais afastado dos restantes subgrupos, ou seja, que existam taxas mais elevadas de próclise, uma vez que é esse o padrão generalizado de colocação de clíticos em francês. 
b) Tempo de exposição formal

Relativamente à variável de TEF, não é linear que um maior TEF em português tenha efeitos no desenvolvimento de clíticos. ${ }^{2}$ Se o TEF ao português desempenhar um papel no desenvolvimento bilingue, espera-se que quanto maior o tempo de exposição formal ao português, maior será a taxa de produção de clíticos e, consequentemente, menor será a taxa de omissão. Espera-se ainda que haja uma taxa mais alta de colocação de clíticos alvo, ou seja, maior taxa de ênclise em contextos de ênclise e maior taxa de próclise em contextos de próclise, à medida que o TEF aumenta. Este aumento nas taxas de produção de clíticos e na produção-alvo da colocação de clíticos em função do aumento de TEF ao português poderá eventualmente ser esperado, uma vez que os clíticos (designados pronomes átonos nos documentos orientadores) são objeto de ensino formal, estando contemplados nos programas de português a partir de níveis iniciais. A substituição de grupos nominais por pronomes clíticos e a sua mudança de posição em função da presença de negação ou de outros elementos está contemplada nesses documentos (veja-se o QuaREPE: Grosso et al., 2011, e o Referencial Camões PLE, no nível $\mathrm{A}^{3}$ ). Contudo, pode também pensar-se que o desenvolvimento de clíticos depende menos de ensino formal do que outros fenómenos claramente associados a registos mais formais, como orações adverbiais concessivas (Costa, 2010) ou uso de conjuntivo em orações subordinadas (Flores, Santos, Jesus \& Marques, 2017). Por outro lado, um maior TEF ao português está geralmente também associado a um maior TEF ao francês, língua de ensino maioritária. Não é, por conseguinte, evidente que um maior TEF ao português determine produção e colocação-alvo de clíticos em crianças a frequentar os primeiros anos de escolaridade.

\section{Metodologia}

\subsection{Critérios para definição das variáveis DL e TEF}

Como referido na secção 3, a DL pode ser calculada com recurso a diversas tarefas. Para a nossa investigação optámos por aplicar uma adaptação do questionário parental LITMUS-PABIQ (Tuller, 2015) que nos permitiu recolher informações relativas à idade de início de exposição à língua, a frequência de exposição à língua em idade precoce, o número de contextos em que se iniciou a exposição à língua (com os pais, avós, escola...), quais as línguas usadas na interação criança vs. pais, irmãos, outros cuidadores, amigos, entre outras informações. O questionário foi distribuído aos pais das crianças em papel e via Google Forms. Tal como previsto no LITMUS-PABIQ, o Índice de Dominância Linguística (IDL) foi calculado subtraindo a pontuação obtida no francês à pontuação obtida no português. Após o cálculo do IDL, os informantes foram distribuídos pelos seguintes subgrupos:

i) Bilingues equilibrados - pontuação entre -6 e +6 ;

ii) Bilingues dominantes a português - pontuação superior a 6 ;

iii) Bilingues dominantes a francês - pontuação inferior a - 6 .

As crianças dominantes a português são também, de acordo com as respostas do questionário, aquelas em que há um maior uso do português do que do francês em casa por ambos os pais.

\footnotetext{
${ }^{2}$ Testámos também um grupo de crianças falantes da variedade brasileira do português, que estão expostas à variedade europeia do português na escola. Para essas crianças, é muito claro que se espera encontrar desenvolvimento na produção de clíticos com a exposição ao ensino formal e à variedade europeia do português. Optámos por não incluir aqui os dados dessas crianças por serem em número reduzido quando cruzamos as variáveis faixa etária e dominância linguística, mas esta foi também uma das razões para incluirmos a variável TEF à variedade europeia do português.

${ }^{3}$ Documento disponível em: https://www.instituto-camoes.pt/activity/centro-virtual/referencial-camoes-ple.
} 
O TEF foi calculado através da diferença entre a data de início da frequência da classe de português na Secção Internacional do Lycée International Saint-Germain-en-Laye e a data de aplicação dos testes. Posteriormente os informantes foram divididos segundo os seguintes subgrupos:

a) subgrupo 1: sem exposição formal / até 1 ano de exposição formal;

b) subgrupo 2: de 2 a 4 anos de exposição formal;

c) subgrupo 3: $\geq 5$ anos de exposição formal. ${ }^{4}$

Nesta divisão, procurou-se ter subgrupos correspondentes a diferentes níveis de alfabetização: um subgrupo de crianças com pouco ou nenhum TEF ao português, com um processo de alfabetização ainda em fase inicial, um subgrupo com algum TEF e um subgrupo com um TEF superior a quatro anos, o que corresponde a um estádio em que se espera que a alfabetização já esteja estabilizada.

\subsection{Participantes}

Neste estudo participaram 32 crianças com idades compreendidas entre os 4 e os 11 anos de idade (média $=8,1 ; \mathrm{DP}=2$ ). Destas 32 crianças, foi possível calcular o IDL para 30, com idades compreendidas entre os $4 \mathrm{e}$ os 11 anos de idade (média $=8,1$; DP $=2,1$ ) Considerando a variável IDL, os 30 informantes foram distribuídos pelos grupos representados no gráfico 1. Destas 30 crianças, 21 participaram na tarefa de produção (Gráfico 2) e 18 participaram na tarefa de colocação (Gráfico 3$)^{5}$.

- PE dominante $\square$ FR dominante $\square$ Bilingues equilibrados

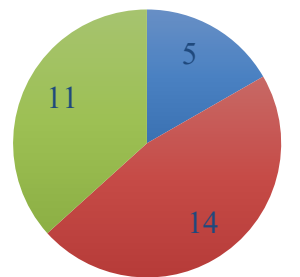

Gráfico 1. Distribuição dos participantes pelos subgrupos de IDL.

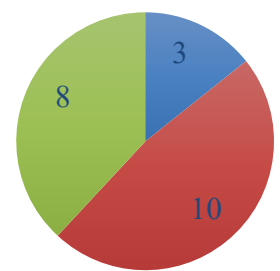

Gráfico 2. Participantes da tarefa de produção.

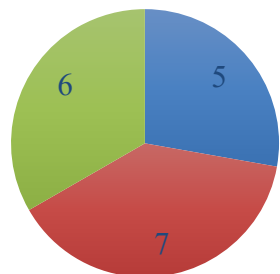

Gráfico 3. Participantes da tarefa de colocação.

\footnotetext{
${ }^{4}$ Como observa um revisor anónimo, as variáveis dominância linguística e TEF podem naturalmente sobrepor-se, uma vez que um maior TEF corresponde também a um maior tempo de exposição à língua. Tencionamos em trabalho futuro cruzar estas duas variáveis. Note-se, ainda assim, que, neste caso, as crianças são escolarizadas maioritariamente em francês, ocupando a escolarização em português apenas seis horas por semana. Há, assim, uma assimetria entre o tempo de exposição formal ao francês e o tempo de exposição formal ao português. Note-se que, no nosso estudo inicial, incluímos também crianças que falam a variedade brasileira do português em casa, sendo expostas à variedade europeia do português na escola. Para este grupo, que decidimos não incluir neste artigo por ter um número insuficiente de crianças, a exposição formal é crucial para o desenvolvimento de clíticos acusativos e padrões de colocação de clíticos, uma vez que há diferenças nestes aspetos gramaticais entre as variedades europeia e brasileira do português.

${ }^{5}$ Devido às restrições temporais para a aplicação dos testes nem sempre foi possível que a mesma criança participasse nas duas tarefas.
} 
Das 32 crianças, 27 reuniram condições para integrarem os grupos de TEF ${ }^{6}$. Estas 27 crianças têm idades compreendidas entre os 6 e os 11 anos de idade (média $=8,8 ; \mathrm{DP}=1,3$ ). Considerando a variável TEF, os 27 informantes foram distribuídos pelos grupos representados no Gráfico 4. Destas 27 crianças, 17 participaram na tarefa de produção (Gráfico 5) e 17 participaram na tarefa de colocação (Gráfico 6).

\section{- Subgrupo $1 \quad$ Subgrupo $2 \quad$ Subgrupo 3}

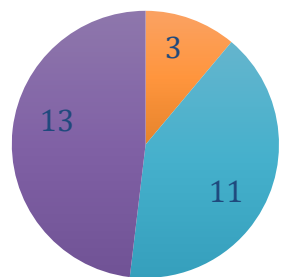

Gráfico 1 Distribuição dos participantes pelos subgrupos de TEF.

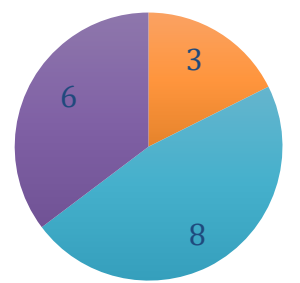

Gráfico 5 Participantes da tarefa de produção.

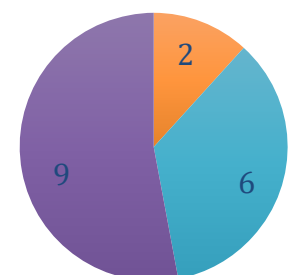

Gráfico 6 Participantes da tarefa de colocação.

Todas as crianças bilingues residem em França e frequentam o ensino regular francês no Lycée International Saint-Germain-en-Laye e na École Maternelle et Primaire Normandie-Niémen - Le Pecq. Duas vezes por semana, num total de 6 horas, frequentam aulas de português. A variedade falada pela professora nas aulas é o PE. Todas as crianças estão expostas ao português (variedade europeia) e ao francês em casa.

\subsection{Procedimento}

A primeira tarefa aplicada a estes informantes foi um teste de produção induzida, adaptado de Nardelli e Lobo (2017).

O teste continha 38 itens ( 4 de treino e 34 de teste), que induziam a produção de clíticos acusativos e reflexos em diferentes contextos sintáticos:

a) clítico acusativo, frase simples - 12 itens;

b) clítico acusativo, ilha - 12 itens;

c) clítico reflexo, frase simples - 10 itens.

Estes três contextos sintáticos permitem-nos verificar se as crianças fazem distinção entre os contextos em que a omissão é permitida em PE (clíticos acusativos em frases simples) e os contextos em que esta não é permitida na gramática adulta do PE (clíticos reflexos; clíticos acusativos em contexto de ilha).

Apresentamos, de seguida, imagens exemplificativas das condições deste teste.

\footnotetext{
${ }^{6}$ Uma vez que se trata de exposição formal à língua, para a determinação do efeito de TEF considerámos apenas os participantes que frequentavam o primeiro ciclo de escolaridade.
} 


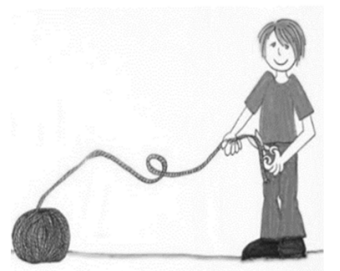

Figura 1 Exemplo da condição de clítico acusativo, frase simples.

Investigador: Temos aqui um rapaz e um novelo de lã. O que é que o rapaz está a fazer ao novelo de lã?

Resposta esperada: Está a cortá-lo./Está a cortar [-].

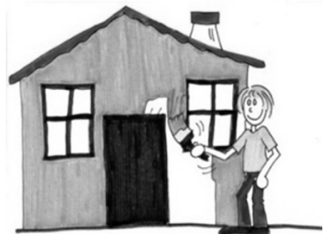

Figura 2 Exemplo da condição de clítico acusativo, ilha.

Investigador: O homem pintou a casa e a casa ficou azul. Porque é que a casa ficou azul? A casa ficou azul porque o homem...

Resposta esperada: ...a

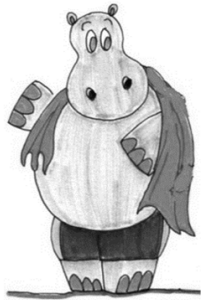

Figura 3 Exemplo da condição de clítico reflexo.

Investigador: O hipopótamo saiu da água e pegou numa toalha. O que é que o hipopótamo está a fazer?

Resposta esperada: Está a limpar-se (secar-se).

As respostas foram classificadas de acordo com as seguintes categorias: a) produção de clítico-alvo; b) omissão; c) produção de grupo nominal pleno (DP); d) outra resposta, e) ausência de resposta.

A segunda tarefa aplicada foi também um teste de produção induzida, adaptado de Costa, Fiéis \& Lobo (2015), que permite testar a aquisição da colocação de clíticos em PE.

O teste continha 40 itens ( 4 de treino e 36 de teste) que induziam a produção de um clítico em diferentes contextos de próclise e em contextos de ênclise distribuídos pelas seguintes condições:

a) Frases simples sem proclisador (ênclise) - 8 itens;

b) Frases simples com negação (próclise) - 4 itens;

c) Frases simples com sujeitos negativos 'ninguém' (próclise) - 4 itens;

d) Frases simples com sujeitos DP quantificados 'todos' (próclise) - 4 itens;

e) Frases simples com advérbio 'já' (próclise) - 4 itens;

f) Orações completivas modo indicativo (próclise) - 4 itens;

g) Orações completivas modo conjuntivo (próclise) - 4 itens;

h) Orações subordinadas adverbiais com 'porque' (próclise) - 4 itens.

Sabe-se, de estudos anteriores, que o clítico se é o que deixa de ser omitido mais cedo e o que apresenta menores taxas de omissão (Silva, 2008). Isto mesmo foi verificado em Nardelli \& Lobo (2017), para bilingues português-espanhol, e no nosso primeiro estudo com bilingues português-francês (Tomaz et al., 2019). Por este mesmo motivo, neste teste, só foi utilizado o clítico se.

Apresentamos, de seguida, duas imagens representativas das condições desta tarefa. 


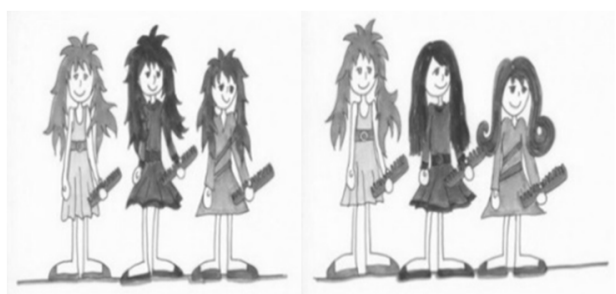

Figura 4 Exemplo da condição frase simples com negação (próclise).

Investigador: [imagem da direita] Estas duas meninas usaram o pente e estão agora penteadas. Mas esta menina continua despenteada. O que é que ela não fez?

Resposta esperada: Não se penteou.

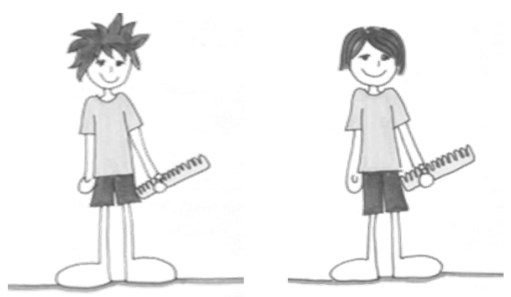

Figura 5 Exemplo da condição frase simples sem proclisador (ênclise).

Investigador: [imagem da esquerda] Este menino está todo despenteado.

[imagem da direita] Mas tem um pente na mão. O que é que o menino fez?

Resposta esperada: Penteou-se.

Em ambas as tarefas, todos os participantes foram testados individualmente. As respostas foram anotadas numa folha de registo, gravadas em formato de áudio e posteriormente transcritas e codificadas num ficheiro Excel. Após a apresentação de uma imagem em computador, pedia-se ao participante que respondesse a uma questão ou que completasse uma frase.

\subsection{Análise estatística}

Para a análise estatística, recorremos ao teste não-paramétrico de Wilcoxon conduzido no programa R. Para variáveis intrassujeitos, usámos o paired samples Wilcoxon test e para as variáveis intersujeitos usámos o unpaired two-samples Wilcoxon test. Como descrito na literatura, consideramos um valor estatisticamente significativo sempre que o valor de $p$ é inferior ou igual a 0.05 (Linck \& Cunnings, 2015).

\section{Resultados}

\begin{tabular}{|c|c|c|c|}
\hline & PE dominante & FR dominante & Bilingues equilibrados \\
\hline Clítico & $36.1 \%$ & $5.8 \%$ & $22.9 \%$ \\
\hline Omissão & $5.6 \%$ & $56.7 \%$ & $46.9 \%$ \\
\hline DP & $47.2 \%$ & $30 \%$ & $17.7 \%$ \\
\hline Outra & $11.1 \%$ & $7.5 \%$ & $12.5 \%$ \\
\hline
\end{tabular}

Tabela 1 Resultados globais para o contexto de clítico acusativo, frase simples (variável IDL)

Como podemos verificar através da tabela 1 , que nos mostra os resultados obtidos para a condição de clíticos acusativos frases simples, o subgrupo PE dominante é o subgrupo que tem maior taxa de produção de clíticos. As diferenças encontradas entre o subgrupo PE dominante e o subgrupo FR dominante (PE) são estatisticamente significativas $(p<.001)$. Se compararmos os subgrupos PE dominante e Bilingues equilibrados $(\mathrm{PE})$, não existe diferença estatisticamente significativa $(p=.1284)$. Relativamente à taxa de omissão, podemos verificar que o subgrupo FR dominante é o que tem uma taxa de omissão mais elevada face aos outros 
subgrupos. A analise estatística demonstra que apenas existem diferenças significativas entre os subgrupos FR dominante e PE dominante $(p<.001)$.

\begin{tabular}{|c|c|c|c|}
\hline & PE dominante & FR dominante & Bilingues equilibrados \\
\hline Clítico & $72.2 \%$ & $16.7 \%$ & $31.3 \%$ \\
\hline Omissão & $11.1 \%$ & $38.3 \%$ & $44.8 \%$ \\
\hline DP & $13.9 \%$ & $36.7 \%$ & $15.6 \%$ \\
\hline Outra & $2.8 \%$ & $8.3 \%$ & $8.3 \%$ \\
\hline
\end{tabular}

Tabela 2 Resultados globais para o contexto de clítico acusativo, ilha (variável IDL)

Em relação à condição de clíticos acusativos em contexto de ilhas, podemos verificar através dos resultados presentes na Tabela 2 que, tal como na condição de clíticos acusativos em contexto de frases simples, o subgrupo PE dominante tem maior taxa de produção de clíticos que os restantes subgrupos. As diferenças encontradas entre os subgrupos PE dominante e FR dominante, bem como entre os subgrupos PE dominante e Bilingues equilibrados são estatisticamente significativas $(p<.001$, para PE dominante vs. FR dominante; $p<$ .001 , para PE dominante vs. Bilingues equilibrados). Relativamente à taxa de omissão, verificamos que o subgrupo PE dominante é o que apresenta menor taxa relativamente aos outros dois subgrupos. As diferenças encontradas são estatisticamente significativas (PE dominante vs. FR dominante $p<.001$; PE dominante vs. Bilingues equilibrados $p<.001)$.

\begin{tabular}{|c|c|c|c|}
\hline & PE dominante & FR dominante & Bilingues equilibrados \\
\hline Clítico & $76.7 \%$ & $55 \%$ & $73.8 \%$ \\
\hline Omissão & $3.3 \%$ & $17 \%$ & $6.3 \%$ \\
\hline DP & - & $1 \%$ & - \\
\hline Outra & $20 \%$ & $26 \%$ & $20 \%$ \\
\hline N.R. & - & $1 \%$ & - \\
\hline
\end{tabular}

Tabela 3 Resultados globais para o contexto de clítico reflexo (variável IDL)

Quanto à condição de clíticos reflexos, podemos verificar através dos resultados presentes na Tabela 3 que, tal como nas condições anteriores, o subgrupo PE dominante tem maior taxa de produção de clíticos que os restantes subgrupos. As diferenças encontradas entre os subgrupos PE dominante e FR dominante, bem como entre os subgrupos FR dominante e Bilingues equilibrados, são estatisticamente significativas $(p=.03459$ e $p$ $=.009738$, respetivamente). Entre os subgrupos PE dominante e Bilingues equilibrados, não há diferenças significativas na taxa de produção de clíticos. Quanto à taxa de omissão, o subgrupo FR dominante é o que apresenta maior taxa face aos restantes subgrupos. A analise estatística revela que a diferença encontrada entre o subgrupo FR dominante e PE dominante se encontra próximo do limiar da significância $(p=.0589)$ e é significativa entre FR dominante e Bilingues equilibrados $(p=.00293)$.

Nas tabelas 4, 5 e 6 são apresentados os resultados da tarefa de produção de clíticos quando considerada a variável TEF. 


\begin{tabular}{|c|c|c|c|}
\hline & $\begin{array}{c}\text { Subgrupo 1 } \\
\text { sem exposição formal / até 1 ano de } \\
\text { exposição formal }\end{array}$ & $\begin{array}{c}\text { Subgrupo 2 } \\
\text { de 2 a 4 anos de exposição } \\
\text { formal }\end{array}$ & $\begin{array}{c}\text { Subgrupo 3 } \\
\geq 5 \text { anos de exposição } \\
\text { formal }\end{array}$ \\
\hline Clítico & $8.3 \%$ & $32.3 \%$ & $12.5 \%$ \\
\hline Omissão & $22.2 \%$ & $49 \%$ & $34.7 \%$ \\
\hline DP & $55.6 \%$ & $13.5 \%$ & $43.1 \%$ \\
\hline Outra & $13.9 \%$ & $5.2 \%$ & $9.7 \%$ \\
\hline
\end{tabular}

Tabela 4 Resultados globais para o contexto de clítico acusativo, frase simples (variável TEF)

\begin{tabular}{|c|c|c|c|}
\hline & $\begin{array}{c}\text { Subgrupo 1 } \\
\text { sem exposição formal / até 1 ano de } \\
\text { exposição formal }\end{array}$ & $\begin{array}{c}\text { Subgrupo 2 } \\
\text { de 2 a 4 anos de exposição } \\
\text { formal }\end{array}$ & $\begin{array}{c}\text { Subgrupo 3 } \\
\geq 5 \text { anos de exposição } \\
\text { formal }\end{array}$ \\
\hline Clítico & $47.2 \%$ & $43.8 \%$ & $27.8 \%$ \\
\hline Omissão & $33.3 \%$ & $39.6 \%$ & $16.7 \%$ \\
\hline DP & $13.9 \%$ & $13.5 \%$ & $48.6 \%$ \\
\hline Outra & $5.6 \%$ & $3.1 \%$ & $6.9 \%$ \\
\hline
\end{tabular}

Tabela 5 Resultados globais para o contexto de clítico acusativo, ilhas (variável TEF)

\begin{tabular}{|c|c|c|c|}
\hline & $\begin{array}{c}\text { Subgrupo 1 } \\
\text { sem exposição formal / até 1 ano de } \\
\text { exposição formal }\end{array}$ & $\begin{array}{c}\text { Subgrupo 2 } \\
\text { de 2 a 4 anos de exposição } \\
\text { formal }\end{array}$ & $\begin{array}{c}\text { Subgrupo 3 } \\
\geq 5 \text { anos de exposição } \\
\text { formal }\end{array}$ \\
\hline Clítico & $76.7 \%$ & $66.3 \%$ & $71.2 \%$ \\
\hline Omissão & $3.3 \%$ & $12.5 \%$ & $6.7 \%$ \\
\hline Outra & $20 \%$ & $21.3 \%$ & $21.7 \%$ \\
\hline
\end{tabular}

Tabela 6 Resultados globais para o contexto de clítico reflexo (variável TEF)

Se o TEF fosse determinante, seria esperado que, com o aumento do número de anos de exposição formal à língua, a taxa de clíticos aumentasse e que, consequentemente, a taxa de omissão diminuísse. No entanto, o comportamento dos participantes do grupo PE/FR não segue a tendência esperada. Estes dados levam-nos a concluir que a variável TEF não tem influência no desempenho dos falantes bilingues PE/FR.

Relativamente ao teste de colocação de clíticos, apresentamos de seguida os resultados obtidos.

\begin{tabular}{|c|c|c|c|c|}
\hline & & PE dominante & FR dominante & Bilingues equilibrados \\
\hline \multirow{4}{*}{$\begin{array}{c}\text { Contextos de } \\
\text { ênclise }\end{array}$} & Ênclise & $90 \%$ & $48.2 \%$ & $58.3 \%$ \\
\hline & Próclise & - & $32.1 \%$ & $20.8 \%$ \\
\hline & Omissão & - & $5.4 \%$ & $6.3 \%$ \\
\hline & Outra & $10 \%$ & $14.3 \%$ & $14.6 \%$ \\
\hline & & & & \\
\hline \multirow{5}{*}{$\begin{array}{c}\text { Contextos de } \\
\text { próclise }\end{array}$} & Ênclise & $46.4 \%$ & $41.3 \%$ & $32.7 \%$ \\
\hline & Próclise & $47.1 \%$ & $35.7 \%$ & $58.9 \%$ \\
\hline & Omissão & $2.1 \%$ & $9.2 \%$ & $2.4 \%$ \\
\hline & Outra & $4.3 \%$ & $10.7 \%$ & $6 \%$ \\
\hline & Redobro & - & $3.1 \%$ & - \\
\hline
\end{tabular}

Tabela 7 Resultados globais para os contextos de ênclise e de próclise (variável IDL) 
$\mathrm{Na}$ tabela 7 , podemos verificar que os três subgrupos têm comportamentos diferentes relativamente à colocação de clíticos. O subgrupo PE dominante é o único grupo que apresenta ênclise categórica no contexto de ênclise. Os restantes subgrupos têm registo de próclise nos contextos de ênclise. O subgrupo FR dominante, aquele em que o uso do português em casa é menor, é o único subgrupo em que o padrão de colocação é idêntico em ambos os contextos, ou seja, estas crianças não fazem uma distinção entre contextos de ênclise e de próclise. O subgrupo de bilingues equilibrados revela uma preferência por ênclise em contextos de ênclise e por próclise em contextos de próclise, sendo essa preferência significativa (próclise vs. ênclise em contextos de ênclise $p=$ .003595 ; próclise vs. ênclise em contextos de próclise $p<.001)$.

\begin{tabular}{|c|c|c|c|c|}
\hline & & $\begin{array}{c}\text { Subgrupo } 1 \\
\text { sem exposição formal / até } 1 \text { ano de } \\
\text { exposição formal }\end{array}$ & $\begin{array}{c}\text { Subgrupo } 2 \\
\text { de } 2 \text { a } 4 \text { anos de exposição } \\
\text { formal } \\
\end{array}$ & $\begin{array}{c}\text { Subgrupo } 3 \\
\geq 5 \text { anos de exposição } \\
\text { formal } \\
\end{array}$ \\
\hline \multirow{2}{*}{$\begin{array}{l}\text { Contextos } \\
\text { de ênclise }\end{array}$} & Ênclise & $100 \%$ & $68.2 \%$ & $88.7 \%$ \\
\hline & Próclise & - & $31.8 \%$ & $11.3 \%$ \\
\hline \multirow{3}{*}{$\begin{array}{l}\text { Contextos } \\
\text { de próclise }\end{array}$} & Ênclise & $38.5 \%$ & $46.2 \%$ & $55.5 \%$ \\
\hline & Próclise & $61.5 \%$ & $50 \%$ & $41.8 \%$ \\
\hline & Redobro & - & $3.8 \%$ & $2.7 \%$ \\
\hline
\end{tabular}

Tabela 8 Resultados globais para os contextos de ênclise e de próclise (variável TEF)

Relativamente à tarefa de colocação de clíticos, e considerando a variável TEF, podemos concluir, através dos dados presentes na tabela 8 , que o comportamento dos participantes demonstra que esta variável não tem influência no seu desempenho. Com o aumento do número de anos de exposição formal à língua seria esperado um aumento da produção de clíticos alvo em contextos de ênclise e de próclise, ou seja, seria esperado que a taxa de ênclise em contextos de ênclise aumentasse entre grupos e, consequentemente, a taxa de próclise diminuísse. Já para os contextos de próclise seria esperado que a taxa de próclise aumentasse e que a taxa de ênclise diminuísse. Contudo, isto apenas se verifica em contextos de ênclise do subgrupo 2 para o subgrupo 3, quer com a taxa de ênclise quer com a taxa de próclise. Nos contextos de próclise não se verifica o esperado.

\section{Discussão e conclusões}

Retomemos as questões e hipóteses de investigação apresentadas na secção 4.

A primeira questão dizia respeito aos efeitos de dominância linguística no desempenho das crianças. Tendo em conta resultados de estudos anteriores relativamente ao desenvolvimento bilingue de propriedades morfossintáticas de desenvolvimento tardio, previa-se que o subgrupo PE dominante fosse o subgrupo em que se esperava que a taxa de omissão fosse inferior. À semelhança de estudos anteriores, que mostraram que apenas as crianças que têm maior exposição à língua minoritária em contexto familiar têm desempenhos mais próximos dos monolingues (Flores, Santos, Jesus \& Marques, 2017), também o nosso estudo mostrou desempenhos mais próximos dos monolingues no grupo PE dominante. Verificámos que existem diferenças significativas entre os subgrupos PE dominante e FR dominante. Entre o subgrupo de Bilingues Equilibrados e FR dominante apenas se verificaram diferenças significativas no contexto de clíticos reflexos. Para além disso, à semelhança do que se verificou em estudos anteriores para a variável faixa etária em monolingues e bilingues (e.g. Nardelli \& Lobo, 2017, 2018), verificamos aqui que os clíticos acusativos são mais sensíveis do que os reflexos a efeitos de dominância linguística. Enquanto no contexto acusativo há diferenças significativas entre os bilingues PE dominante e os restantes subgrupos, no contexto reflexo só o grupo FR dominante se distingue dos restantes. 
Relativamente à colocação de clíticos, também se previa que o subgrupo PE dominante se aproximasse mais dos monolingues e que o subgrupo FR dominante teria um padrão de colocação mais afastado do subgrupo PE dominante e Bilingues equilibrados. Os dados obtidos permitiram concluir que os três subgrupos têm um comportamento diferente. Tal como em estudos anteriores, verificamos que o subgrupo PE dominante apresenta um padrão de comportamento semelhante ao dos monolingues PE, ou seja, ênclise categórica em contextos de ênclise e com variação entre ênclise e próclise nos contextos de próclise. O subgrupo FR dominante é o único em que o padrão de colocação de clíticos é idêntico em ambos os contextos: não fazem distinção entre contextos de ênclise e de próclise. Já o subgrupo de Bilingues Equilibrados apresenta preferência pela ênclise em ênclise e pela próclise em próclise. Os resultados relativos a esta tarefa sugerem que poderá haver transferência do padrão de próclise do francês para o português nos subgrupos FR dominante e Bilingues equilibrados. Pode pensar-se, assim, que os grupos com menor exposição ao português são mais vulneráveis a efeitos de transferência. Comprova-se assim o que muitos estudos anteriores têm mostrado relativamente à aquisição de diferentes fenómenos para a língua minoritária de falantes de herança: só as crianças que têm uma exposição elevada à língua minoritária têm um desempenho que se aproxima do dos falantes monolingues e isto é verdade sobretudo para fenómenos mais complexos, sujeitos a desenvolvimento tardio (Thordardottir, 2014; Unsworth, 2014; Flores, Santos, Jesus \& Marques, 2017; entre outros). Segundo Almeida et al. (2017), a dominância linguística parece exercer influência sobretudo em tarefas em que seja necessário fazer uso do conhecimento lexical e morfossintático, como é o caso dos fenómenos aqui testados. Verificámos que os nossos dados em certa medida refletem isso mesmo, visto que observámos a existência de diferenças significativas entre os subgrupos PE dominante e FR dominante no que às taxas de omissão e produção de clíticos diz respeito. Relativamente à produção, os grupos de bilingues $\mathrm{PE} / \mathrm{FR}$ apresentam padrões de comportamento diferentes entre si.

Considerando que a produção de clíticos envolve uma componente da gramática, a sintaxe, e uma interface externa, o discurso, e que a colocação de clíticos em PE se rege por restrições sintáticas, podemos afirmar, tendo em conta os dados obtidos, que, apesar de estes fenómenos envolverem módulos gramaticais distintos, em ambos houve sensibilidade a efeitos de dominância linguística. Assim, não é claro que os fenómenos na interface sintaxe-discurso sejam mais afetados do que fenómenos que requerem desenvolvimento sintático e lexical. Na verdade, ambos os fenómenos são fenómenos de aquisição relativamente tardia no desenvolvimento monolingue, comparativamente a fenómenos de concordância ou de ordem básica de constituintes. Tendo em conta estudos anteriores para outras línguas que observam diferentes ritmos no desenvolvimento bilingue para diferentes fenómenos de natureza morfossintática ou sintática e semântica (Unsworth, 2014; Tsimpli, 2014; Flores, Santos, Jesus \& Marques, 2017; entre outros), é assim esperado que também a produção e colocação de clíticos seja um fenómeno vulnerável e sensível a efeitos de input e à dominância linguística em particular.

A segunda variável que investigámos foi o tempo de exposição formal à língua minoritária. Relativamente a esta variável, os efeitos esperados eram mais imprevisíveis. Se, por um lado, poderia haver algum efeito da escola na produção e colocação de clíticos, uma vez que este é um tópico contemplado nos conteúdos gramaticais trabalhados desde o primeiro ciclo, por outro lado, não é claro que a escola desenvolva conhecimento explícito especificamente sobre as estruturas testadas. Os resultados obtidos levam-nos a concluir que a variável TEF não teve efeito significativo nos desempenhos das crianças. $\mathrm{Na}$ verdade, embora a estabilização da produção e colocação de clíticos seja mais tardia em português do que em outras línguas, não é uma área cujo desenvolvimento dependa crucialmente da exposição a registos formais, ao contrário de determinados tipos de estruturas adverbiais concessivas ou de outros casos de orações complexas.

Concluímos assim que, tanto na tarefa de produção de clíticos, como na tarefa de colocação de clíticos um maior TEF ao português nas faixas etárias que aqui considerámos não determina uma melhoria no desempenho dos falantes bilingues. Sabendo que a aquisição de clíticos pode ser efetuada sem recurso à exposição formal, o desenvolvimento desta competência linguística nos falantes bilingues não é influenciado por este fator (Pires 
\& Rothman, 2009; Barbosa \& Flores, 2011). No nosso caso, para além de estarem expostas ao português em contexto formal, num horário reduzido, estas crianças estão expostas durante muito mais horas ao francês em contexto formal, ou seja, na maioria dos casos, há não só um aumento de exposição formal ao português, mas também um aumento de tempo de exposição formal ao francês. Seria preciso testarmos estas crianças em francês para percebermos qual o efeito que a exposição ao português tem na colocação de clíticos no francês.

Em síntese, concluímos que a quantidade de input recebido em casa é determinante para o desenvolvimento linguístico de bilingues quando consideramos propriedades linguísticas que necessitam de uma maior quantidade de evidência linguística para estabilizarem, como é o caso dos pronomes clíticos do português, que mobilizam não só conhecimento sintático, mas também discursivo e lexical. Em contrapartida, o tempo de exposição formal nas idades das crianças aqui testadas não mostrou ser determinante para o desenvolvimento da produção e colocação de clíticos nos contextos que testámos. Este será um fenómeno que se desenvolve sobretudo com base no input recebido em contextos de uso quotidiano da língua e que é menos sensível a efeitos de ensino formal.

\section{Referências:}

Almeida, L., Ferré, S., Morin, E., Prévost, P., dos Santos, C. \& Tuller, L. (2017) Identification of bilingual children with specific language impairment in France. Linguistic Approaches to Bilingualism 7 (3-4), pp. 331-358.

Argyri, E., \& Sorace, A. (2007) Crosslinguistic influence and language dominance in older bilingual children. Bilingualism: Language and Cognition 10(1), pp. 79-99.

Barbosa, P. \& Flores, C. (2011) Clíticos no português de herança de emigrantes bilingues de segunda geração. Textos Seleccionados do XXVI Encontro Nacional da Associação Portuguesa de Linguística. Lisboa: APL, pp. 81-98.

Casa Nova, M. (2015) Formas de realização do pronome clítico em português europeu por falantes de herança luso-franceses. Revista Diacrítica 29 (1), pp. 113-145.

Costa, A. L. (2010) Estruturas contrastivas: desenvolvimento do conhecimento explícito e da competência de escrita. Tese de doutoramento. Universidade de Lisboa.

Costa, J. \& Lobo, M. (2006) A aquisição de clíticos em PE: omissão de clíticos ou objecto nulo. Textos Seleccionados do XXI Encontro Nacional da Associação Portuguesa de Linguística. Lisboa: APL, pp. 285293.

Costa, J., M. Lobo \& F. Pratas (2016) Clitic production by Portuguese and Capeverdean children: Omission in bilingualism. Probus 28.2, pp. 271-291.

Costa, J., Lobo, M. \& Silva, C. (2009) Null objects and early pragmatics in the acquisition of European Portuguese. Probus 21 (2), pp. 143-162.

Costa, J., Fiéis, A. \& Lobo, M. (2015) Input variability and late acquisition: clitic misplacement in European Portuguese. Lingua 161, pp. 10-26.

De Houwer, A., M. Bornstein \& D. L. Putnick (2014) A bilingual-monolingual comparison of young children's vocabulary size: Evidence from comprehension and production. Applied Psycholinguistics, 35, pp. 11891211.

Direção de Serviços de Língua e Cultura, Camões, I.P. (2017) Referencial Camões PLE. Lisboa: Camões, Instituto da Cooperação e da Língua I.P. (disponível em: https://www.instituto-camoes.pt/activity/centrovirtual/referencial-camoes-ple).

Flores, C. \& Barbosa, P. (2014) When reduced input leads to delayed acquisition: a study on the acquisition of clitic placement by Portuguese heritage speakers. International Journal of Bilingualism 18 (3), pp. 304-325. 
Flores, C., Barbosa, P. \& Casa Nova, M. (2016) A Closer Look at CrossLinguistic Influence in the Acquisition of Portuguese as a Heritage Language. In S. Grucza, M. Olpinska-Szkieko \& P. Romanowski (orgs.) Bilingual Landscape of the Contemporary World. Frankfurt/Main, London, New York: Peter Lang Verlag, pp. 75-94.

Flores, C. \& Correia, L. (2016) O papel do grau de exposição linguística no desenvolvimento bilingue. In X. Sánches Rei \& M.A. Marques (eds.), As ciências da linguagem no espaço galego-português. Diversidade e convergência. Braga: ILCH/Húmus, pp. 243-261.

Flores, C., A.L. Santos, A. Jesus \& R. Marques (2017) Age and input effects in the acquisition of mood in Heritage Portuguese. Journal of Child Language, 44(4), pp. 795-828.

Gathercole, V. C. M. \& Thomas, E. M. (2009) Bilingual first-language development: Dominant language takeover, threatened minority language take-up. Bilingualism: Language and Cognition 12, pp. 213-237.

Gathercole, V. C. M., Thomas, E. M., Roberts, E., Hughes, C., \& Hughes, E. (2013) Why assessment needs to take exposure into account: Vocabulary and grammatical abilities in bilingual children. In V. C. M. Gathercole (ed.), Issues in the assessment of bilinguals. Bristol: Multilingual Matters, pp. 20-55.

Genesee, F. (1989) Early bilingual development: One language or two? Journal of child language 16 (1) pp. 161-179.

Grohmann, K. K., Papadopoulou, E., \& Themistocleous, C. (2017) Acquiring clitic placement in bilectal settings: interactions between social factors. Frontiers in Communication 2 (5).

Grosjean F. (1997) The bilingual individual. Interpreting 2, pp. 163-87.

Grosso, M. J., (coord.), A. Soares, F. de Sousa, J. Pascoal (2011) QuaREPE. Quadro de Referência para o Ensino Português no Estrangeiro. DGIDC. Min. Educação. (disponível em: http://www.dge.mec.pt/sites/default/files/EEstrangeiro/2012_quarepe_docorientador.pdf, acedido em outubro 2020)

Guasti, M. T. (1993/1994) Verb syntax in Italian child grammar: Finite and nonfinite verbs. Language Acquisition 3:1, pp. 1-40

Hamann, C., Rizzi, L., \& Frauenfelder, U. (1996) On the acquisition of subject and object clitics in French. In H. Clahsen (org.) Generative perspectives on language acquisition. Amesterdam: John Benjamins, pp. 309333.

Haman, E., Wodniecka, Z., Marecka, M., Szewczyk, J., Białecka-Pikul, M., Otwinowska, A., ... \& Kacprzak, A. (2017) How does L1 and L2 exposure impact L1 performance in bilingual children? Evidence from Polish-English migrants to the United Kingdom. Frontiers in Psychology 8, pp. 1444.

Kootstra G.J., \& Doedens W. J. (2016) How multiple sources of experience influence bilingual syntactic choice: immediate and cumulative cross-language effects of structural priming, verb bias, and language dominance. Bilingualism: Language and Cognition 19(4), pp. 710-732.

Kupisch, T. (2008) Dominance, mixing and cross-linguistic influence: On their relation in bilingual development. In P. Guijarro-Fuentes, P. Larrañaga \& J: Clibbens (eds.). First Language Acquisition of Morphology and Syntax: Perspectives across Languages and Learners. Amesterdam: John Benjamins, pp. 209-234.

Linck, J., \& Cunnings, I. (2015) The utility and application of mixed-effects models in second language research. Language Learning 65, pp. 185-207.

Marinis, T. (2000) The acquisition of clitic objects in Modern Greek: Single clitics, clitic doubling, clitic left dislocation. ZAS Papers in Linguistics 15, pp. 259-281.

Martins, A. M. (2013) A posição dos pronomes pessoais clíticos. Em E. Raposo, F. Nascimento, A. Mota, L. Segura \& A. Mendes (Eds.), Gramática do Português (Vol. 2). Lisboa: Fundação Calouste Gulbenkian, pp. 2229-2302. 
Meisel, J. (1989) Early differentiation of languages in bilingual children. In Kenneth Hyltenstam e Loraine Obler (orgs.) Bilingualism across the lifespan: Aspects of acquisition, maturity, and loss. Cambridge, UK: Cambridge University Press, pp. 13-40.

Meisel, J.M. (2007) The weaker language in early child bilingualism: Acquiring a first language as a second language? Applied Psycholinguistics 28 (3), pp. 495-514.

Müller, N. \& Hulk, A. (2001) Crosslinguistic influence in bilingual language acquisition: Italian and French as recipient languages. Bilingualism: Language and Cognition, 4(1), pp. 1-21

Nardelli, M. (2015) Omissão de pronomes clíticos em crianças bilingues português europeu e espanhol ibérico. Dissertação de Mestrado, Universidade Nova de Lisboa.

Nardelli, M. \& Lobo, M. (2017) Omissão de clíticos na aquisição bilingue português-espanhol. Revista da Associação Portuguesa de Linguística 3, pp. 241-263.

Nardelli, M. \& M. Lobo (2018) Clitic omission in bilingual Portuguese-Spanish acquisition. In A. Gavarró (ed.) On the Acquisition of the Syntax of Romance. Amsterdam: John Benjamins, pp. 119-145.

Paradis, J. \& Genesee, F. (1996) Syntactic acquisition in bilingual children: Autonomous orinterdependent? Studies in second language acquisition 18(1), pp. 1-25.

Paradis, J., Tremblay, A., \& Crago, M. (2014). French-English bilingual children's sensitivity to childlevel and language-level input factors in morphosyntactic acquisition. In T. Grüter \& J. Paradis (eds.), Input and experience in bilingual development. Amsterdam/Philadelphia: John Benjamins, pp. 161-180.

Pérez-Leroux, A. T., Pirvulescu, M., \& Roberge, Y. (2008) Null objects in child language: Syntax and the lexicon. Lingua, 118(3), pp. 370-398.

Pérez-Leroux, A. T., Pirvulescu, M. \& Roberge, Y. (2018) Direct objects and Language Acquisition. Cambridge: Cambridge University Press.

Pires, A. \& Rothman, J. (2009) Disentangling sources of incomplete acquisition: an explanation for competence divergence across heritage grammars. International Journal of Bilingualism 13 (2), pp. 211-238.

Pires, A., \& Rothman, J. (2011) An integrated perspective on comparative bilingual differences: Beyond the Interface problem?. Linguistic Approaches to Bilingualism, 1(1), pp. 74-78.

Pirvulescu, M., Pérez-Leroux, A. \& Roberge, Y (2012) A bidirectional study of object omissions in FrenchEnglish bilinguals. In Kurt Braunmüller, Christoph Gabriel \& Barbara Hänel-Faulhaber (eds.), Multilingual individuals and multilingual societies. Amsterdam: John Benjamins, pp. 171-188.

Polinsky, M. (2016) "Cascading consequences of syntactic reorganization: Ellipsis in heritage languages," in Keynote Address at BUCLD 41 (Boston, MA).

Polinsky, M. (2018) Heritage Languages and their Speakers. Cambridge: Cambridge University Press.

Puig-Mayenco E., Cunnings I., Bayram F., Miller D., Tubau S. \& Rothman J. (2018) Language Dominance Affects Bilingual Performance and Processing Outcomes in Adulthood. Frontiers in Psychology 9, pp. 1199.

Raposo, E. P. (1986) On the Null Object Construction in European Portuguese. In. O. Jaeggli \& C. SilvaCorvalán (orgs.) Studies in Romance Linguistics. Dordrecht: Foris, pp. 373-390.

Rinke, E., C. Flores \& A. Sopata (2019) Heritage Portuguese and Heritage Polish in Contact with German. More Evidence on the Production of Objects. Languages, 4(3), 53.

Rodina, Y., T. Kupisch, N. Meir, N. Mitrofanova, O. Urek, M. Westergaard (2020) Internal and External Factors in Heritage Language Acquisition: Evidence From Heritage Russian in Israel, Germany, Norway, Latvia and the United Kingdom. In: Frontiers in Education. Frontiers Media. 5, 20.

Silva, C. (2008) Assimetrias na aquisição de clíticos diferenciados em português europeu. Dissertação de Mestrado, Universidade Nova de Lisboa.

Silva-Corvalán, C., \& Treffers-Daller, J. (2016) Digging into dominance: A closer look at language dominance in bilinguals. Language dominance in bilinguals: Issues of measurement and operationalization, pp. 1-15. 
Thomas, E., N. Williams, L. Jones, S. Davies \& H. Binks (2014) Acquiring complex structures under minority language conditions: Bilingual acquisition of plural morphology in Welsh. Bilingualism: Language and Cognition 17 (3), pp. 478-494.

Thordardottir, E. (2014) The relationship between bilingual exposure and morphosyntactic development. International Journal of Speech Language Pathology.

Tomaz, M., Lobo, M., Madeira, A., Soares-Jesel, C., \& Vaz, S. (2019) Omissão e colocação de clíticos por crianças bilingues Português-Francês. Revista da Associação Portuguesa de Linguística 5, pp. 385-412.

Treffers-Daller, J. (2019) What defines language dominance in bilinguals? Annual Review of Linguistics 5, pp. 375-393.

Tuller, L. (2000) Aspects de la morphosyntaxe du français des sourds. Recherches linguistiques de Vincennes 29, pp. 143-156.

Tuller, L. (2015) Clinical Use of Parental Questionnaires in Multilingual Contexts. Assessing multilingual children: Disentangling bilingualism from language impairment 13, pp. 301-330.

Unsworth, S. (2014) Comparing the role of input in bilingual acquisition across domains. In. T. Grüter \& J. Paradis (eds.) Input and experience in bilingual development. Amsterdam: John Benjamins, pp. 181-201.

Varlokosta, S., Costa, J., Friedmann, N., Gavarró, A., Grohmann, K., ... \& Yatsushiro, K. (2015) A CrossLinguistic Study of the Acquisition of Clitic and Pronoun Production. Language Acquisition 23 (1), pp. 126.

Wang X. (2013) Language dominance in translation priming: evidence from balanced and unbalanced ChineseEnglish bilinguals. Quarterly Journal of Experimental Psychology 66 (4), pp. 727-743.

Wexler, K., Gavarró, A. \& Torrens, V. (2004) Feature checking and object clitic omission in child Catalan and Spanish. In Reineke Bok-Bennema, Bart Hollebrandse, Brigitte Kampers-Manhe \& Petra Sleeman (orgs.), Romance languages and linguistic theory 2002. Amsterdam: John Benjamins, pp. 253-270. 